Supplement of Biogeosciences, 18, 1971-1985, 2021 https://doi.org/10.5194/bg-18-1971-2021-supplement (C) Author(s) 2021. CC BY 4.0 License.

(c) (1)

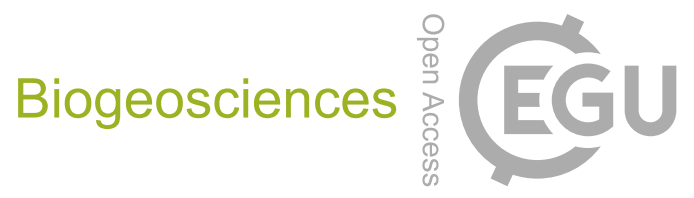

Supplement of

\title{
Improving the monitoring of deciduous broadleaf phenology using the Geostationary Operational Environmental Satellite (GOES) 16 and 17
}

Kathryn I. Wheeler and Michael C. Dietze

Correspondence to: Kathryn I. Wheeler (kiwheel@bu.edu)

The copyright of individual parts of the supplement might differ from the article licence. 


\section{Supplementary Material}

Table S1: Specific PhenoCam Sites and Regions of Interest.

\begin{tabular}{ll}
\hline Site name & PhenoCam site and region of interest \\
\hline Harvard Forest & harvard_DB_0001 \\
Hubbard Brook & hubbardbrooksfws_DB_3000 \\
UMBS & umichbiological_DB_2000 \\
Coweeta & coweeta_DB_0001 \\
Bartlett & bartlettir_DB_1000 \\
Missouri Ozarks & missouriozarks_DB_0001 \\
Morgan Monroe & morganmonroe_DB_1000 \\
Russell Sage & russellsage_DB_0001 \\
Willow Creek & willowcreek_DB_1000 \\
Bull Shoals & bullshoals_DB_1000 \\
Duke & dukehw_DB_1000 \\
Green Ridge & greenridge1_DB_1000 \\
Shenandoah & shenandoah_DB_0001 \\
Marcell & marcell_DB_1000 \\
Shining Rock & \\
\hline \hline
\end{tabular}


Table S2: Credible interval width comparison $p$-values.

\begin{tabular}{lllllll}
\hline Transition & $\begin{array}{l}\text { GOES } \\
\text { and PC }\end{array}$ & $\begin{array}{l}\text { MODIS_N } \\
\text { and PC }\end{array}$ & $\begin{array}{l}\text { MODIS_E } \\
\text { and PC }\end{array}$ & $\begin{array}{l}\text { MODIS_N } \\
\text { and GOES }\end{array}$ & $\begin{array}{l}\text { MODIS_E } \\
\text { and GOES }\end{array}$ & $\begin{array}{l}\text { MODIS_E } \\
\text { and MODIS_N }\end{array}$ \\
\hline Spring Start & 0 & 0 & 0 & 0.07 & 0 & 0.637 \\
Spring Middle & 0 & 0 & 0 & 0.029 & 0 & 0.972 \\
Spring End & 0 & 0 & 0 & 0.023 & 0 & 0.849 \\
Autumn Start & 0.002 & 0.013 & 0 & 0.171 & 0 & 0.269 \\
Autumn Middle & 0.006 & 0.003 & 0 & 0.076 & 0 & 0.323 \\
Autumn End & 0.001 & 0.004 & 0 & 0.215 & 0.026 & 0.929 \\
\hline \hline
\end{tabular}

15

20

25 
Table S3: Summary statistics *Negative indicates the first source is earlier than the second. The width of the bias average credible 40 interval $(\mathbf{C I})$ is given in days.

\begin{tabular}{|c|c|c|c|}
\hline Data Sources & $\mathbf{R}^{2}$ & RMSE (days) & Average Bias* (days; 95\% CI) \\
\hline \multicolumn{4}{|l|}{ Start of Spring: } \\
\hline MODIS NDVI vs. GOES & 0.25 & 12.79 & $-4.99 \pm 0.1$ \\
\hline MODIS EVI vs. GOES & 0.37 & 11.73 & $-6.48 \pm 0.04$ \\
\hline MODIS EVI vs. MODIS NDVI & 0.62 & 5.95 & $-1.48 \pm 0.1$ \\
\hline \multicolumn{4}{|l|}{ Middle of Spring: } \\
\hline MODIS NDVI vs. GOES & 0.3 & 12.34 & $-4.64 \pm 0.05$ \\
\hline MODIS EVI vs. GOES & 0.5 & 10.41 & $-5.7 \pm 0.04$ \\
\hline MODIS EVI vs. MODIS NDVI & 0.55 & 6.81 & $-1.05 \pm 0.04$ \\
\hline \multicolumn{4}{|l|}{ End of Spring: } \\
\hline MODIS NDVI vs. GOES & 0.25 & 12.85 & $-4.3 \pm 0.1$ \\
\hline MODIS EVI vs. GOES & 0.56 & 9.89 & $-4.92 \pm 0.04$ \\
\hline MODIS EVI vs. MODIS NDVI & 0.47 & 8.1 & $-0.62 \pm 0.1$ \\
\hline
\end{tabular}

45 Start of Autumn:

$\begin{array}{lccc}\text { MODIS NDVI vs. GOES } & 0.00 & 17.73 & 5.25 \pm 0.24 \\ \text { MODIS EVI vs. GOES } & 0.00 & 27.18 & -20.09 \pm 0.09 \\ \text { MODIS EVI vs. MODIS NDVI } & 0.00 & 29.24 & -25.34 \pm 0.24\end{array}$

Middle of Autumn:

$\begin{array}{lccc}\text { MODIS NDVI vs. GOES } & 0.34 & 9.72 & -2.89 \pm 0.05 \\ \text { MODIS EVI vs. GOES } & 0.00 & 23.69 & -19.74 \pm 0.06 \\ \text { MODIS EVI vs. MODIS NDVI } & 0.00 & 19.32 & -16.85 \pm 0.06\end{array}$

End of Autumn:

$\begin{array}{lccc}\text { MODIS NDVI vs. GOES } & 0.00 & 17.04 & -11.03 \pm 0.24 \\ \text { MODIS EVI vs. GOES } & 0.00 & 23.98 & -19.39 \pm 0.07 \\ \text { MODIS EVI vs. MODIS NDVI } & 0.00 & 12.64 & -8.36 \pm 0.24\end{array}$




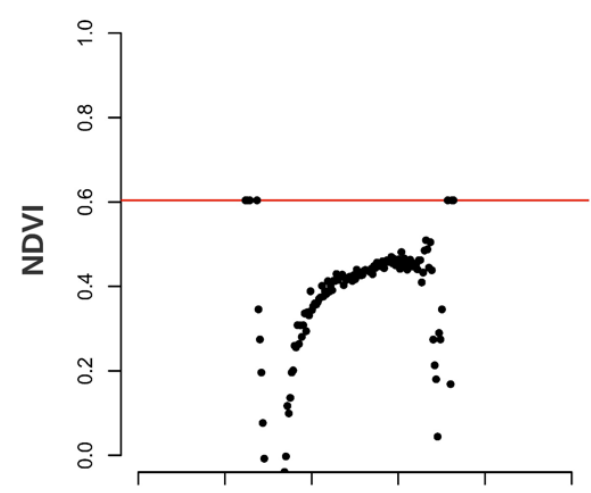

Missouri Ozarks 9 Nov 2019

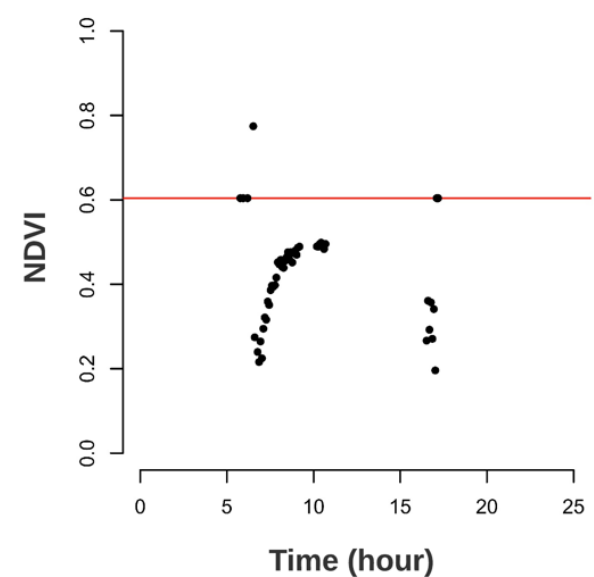

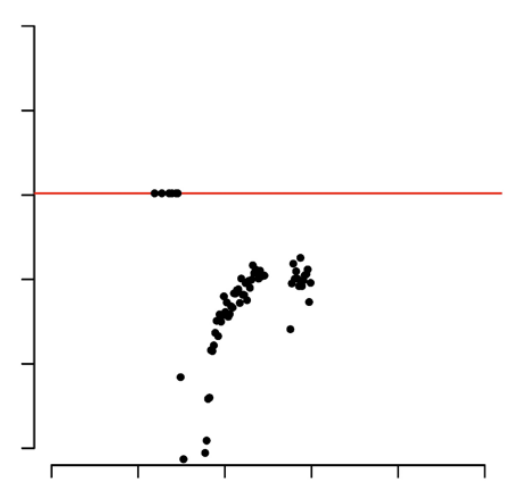

Missouri Ozarks 10 Nov 2019

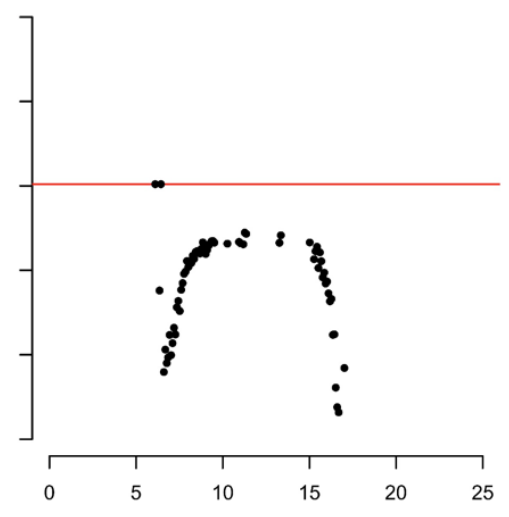

Time (hour)

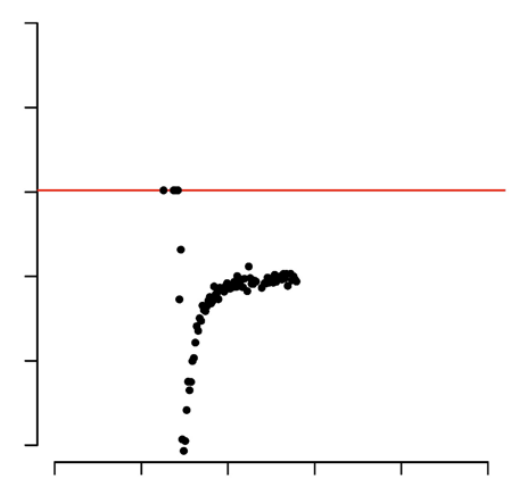

Missouri Ozarks 24 Nov 2019

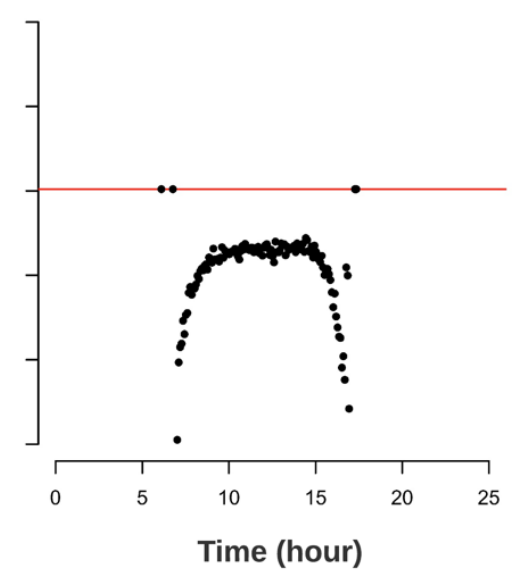

50 Figure S1: Examples of diurnal GOES data for different sites and dates that show the consistent noisy NDVI value of 0.6040 (horizontal red line), which we removed to improve fits. 


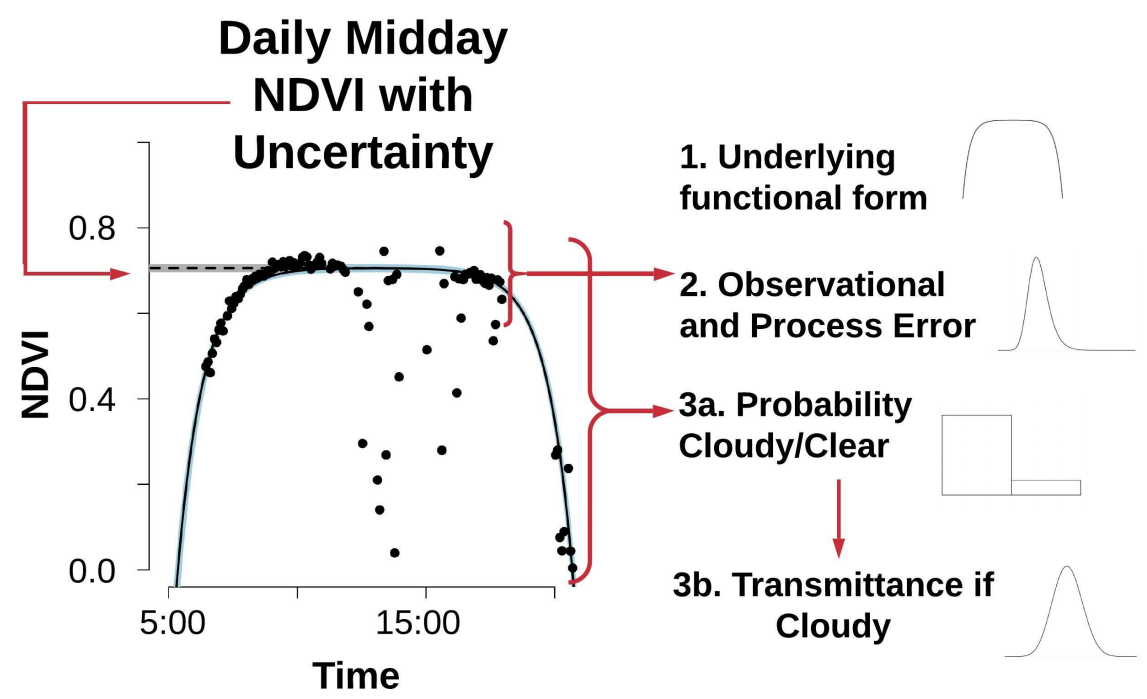

Figure S2: Representation of the GOES diurnal method used to estimate daily midday NDVI values. Reprinted from (Wheeler and Dietze, 2019). The light blue shading indicates the $95 \%$ credible interval (CI) and the dotted horizontal line (with gray shading) indicates the fitted midday maximum NDVI value (and $95 \% \mathrm{CI}$ ). 

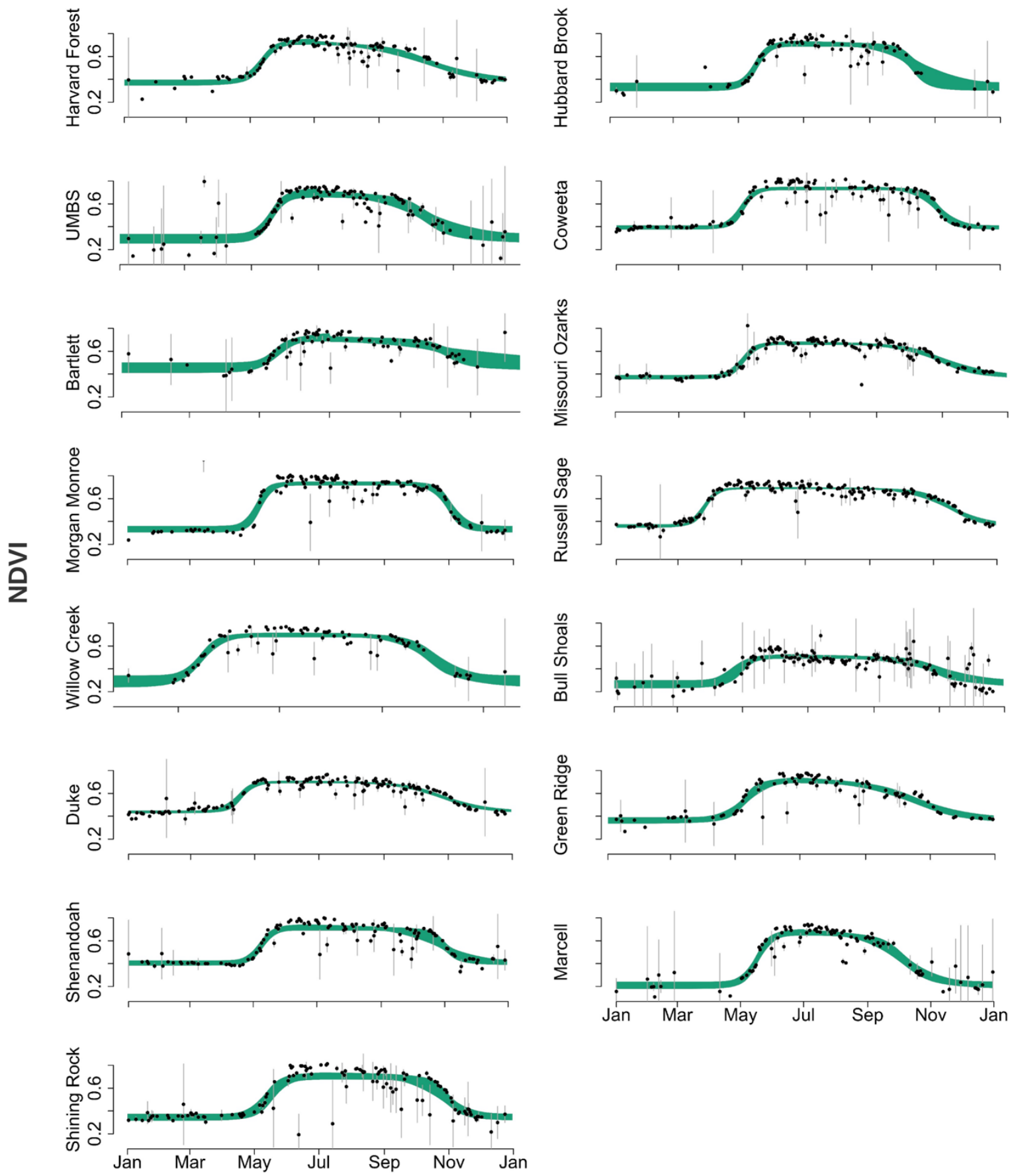

\section{Time}

Figure S3: Phenological fits for GOES data at the different sites for 2018. The shading indicates the $95 \%$ credible intervals (CI). The points indicate the mean of the midday NDVI values from the daily diurnals with the gray vertical lines indicating the $95 \% \mathrm{CI}$ on the daily data. 

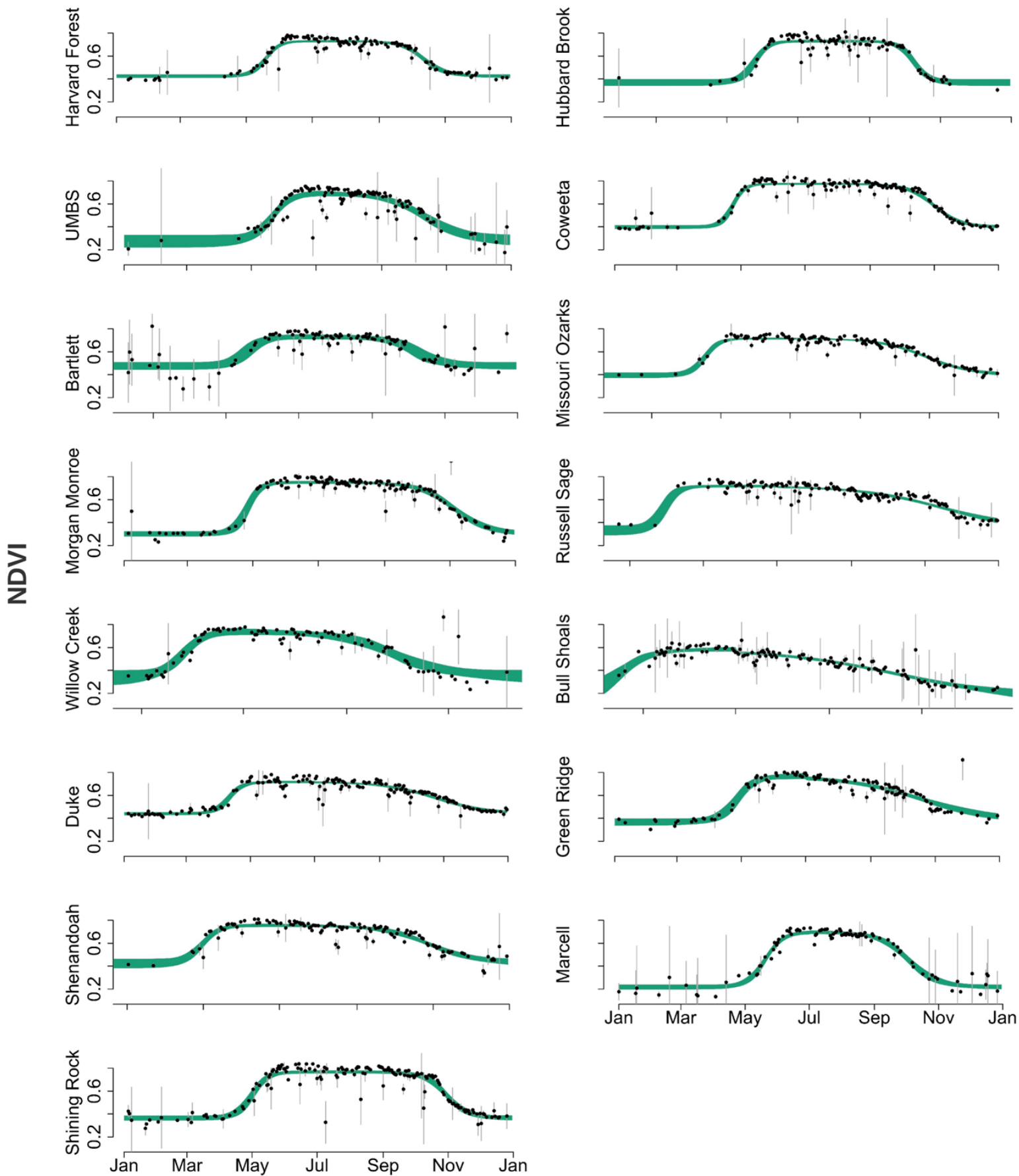

\section{Time}

Figure S4: Phenological fits for GOES data at the different sites for 2019. The shading indicates the $95 \%$ credible intervals (CI). The points indicate the mean of the midday NDVI values from the daily diurnals with the gray vertical lines indicating the $95 \% \mathrm{CI}$ on the daily data. 

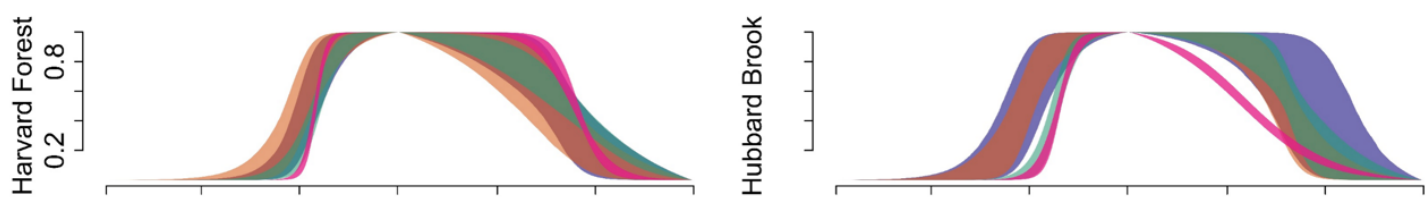

$\left.\sum_{\substack{\infty \\ \infty}}^{\infty}{ }^{\infty}\right]$

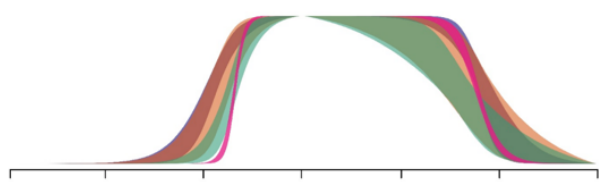

피

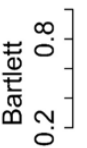
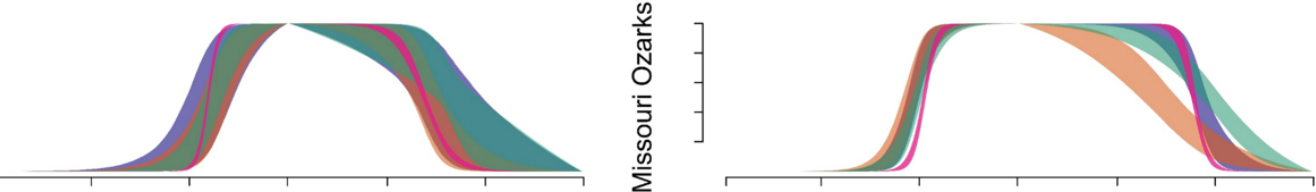

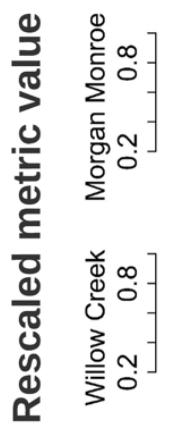
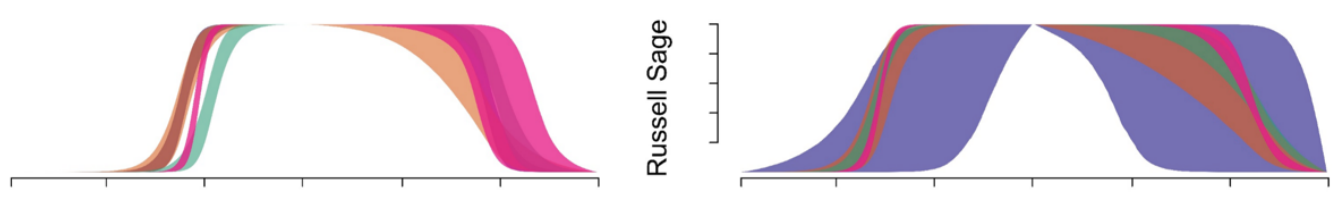

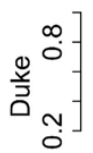
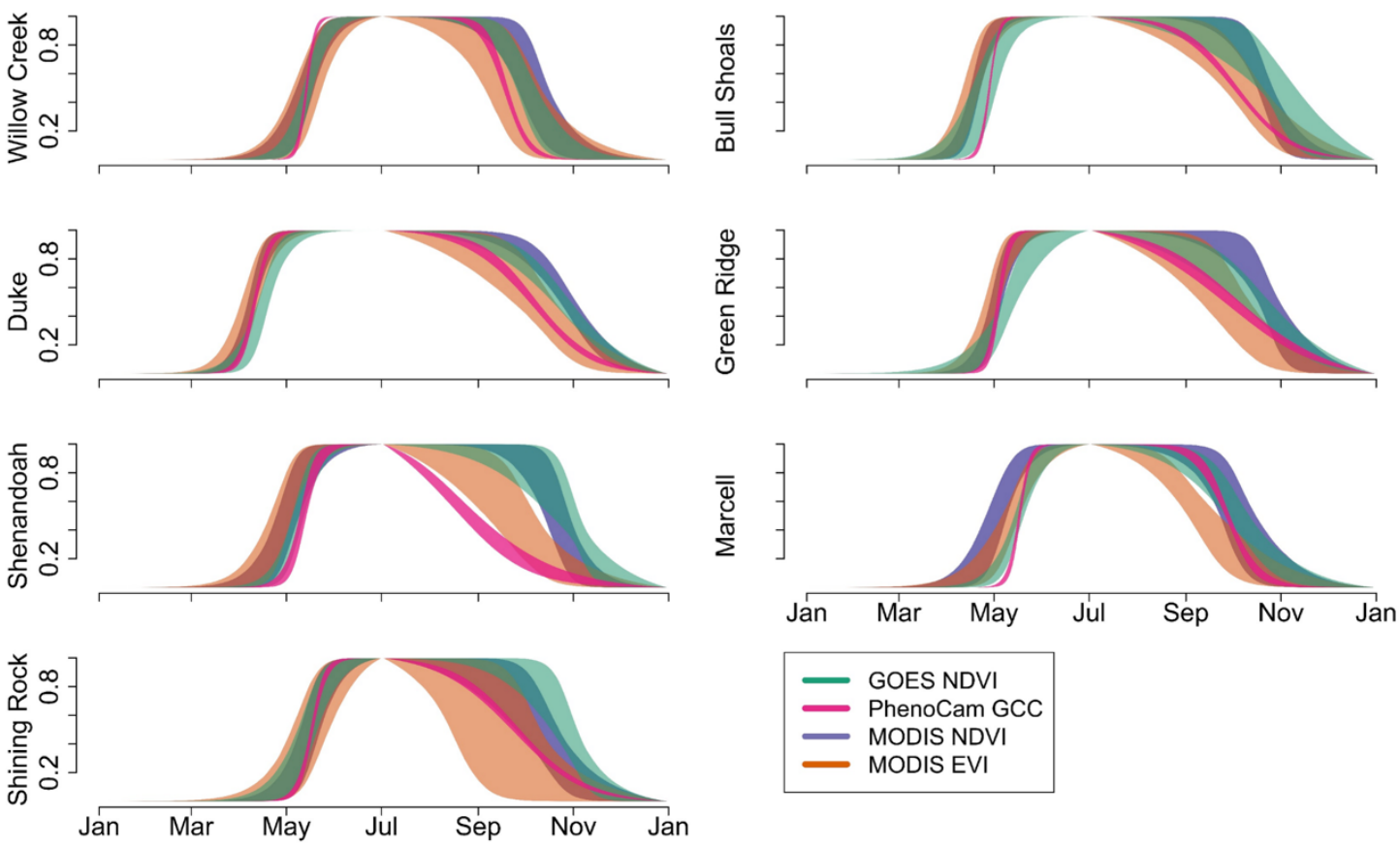

\section{Time}

65 Figure S5: Rescaled 95\% credible intervals for the phenology fits for 2018 for all data sources and sites. 


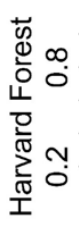

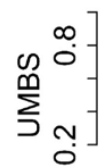

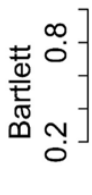

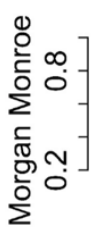

$\left.\begin{array}{l}\frac{\infty}{\infty} \\ \frac{0}{\infty} \\ \frac{0}{\overline{0}} \\ \bar{\infty}\end{array}\right]$

$\left.\begin{array}{l}0 \\ \frac{0}{0} \\ \frac{0}{\alpha} \\ \frac{1}{\Phi} \\ \frac{0}{0}\end{array}\right]$

$\bar{\Phi}$
$\overline{0}$
$\left.\frac{0}{\overline{0}}\right]$

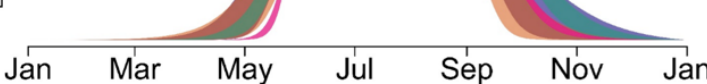

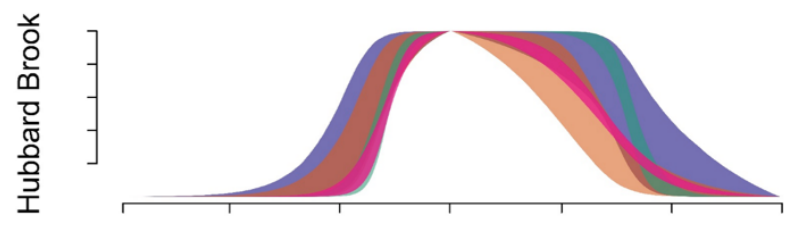

$\left.\begin{array}{ll} & \\ 0 & 0 \\ 0 & 0 \\ 0 & 0 \\ 0 & 0\end{array}\right]$
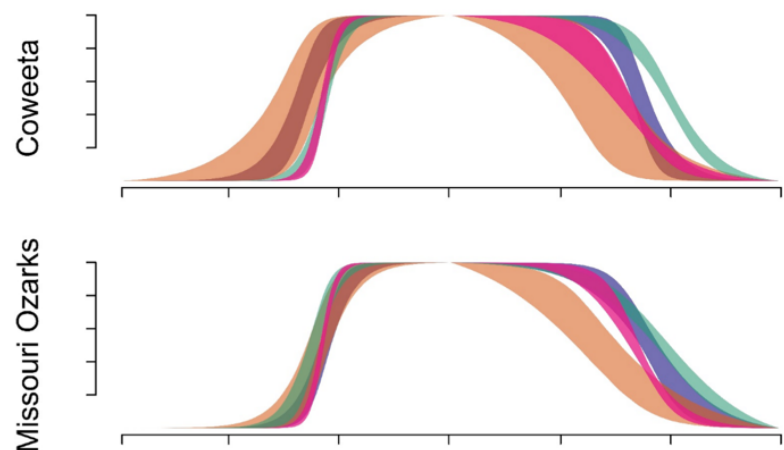

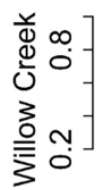

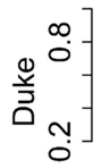

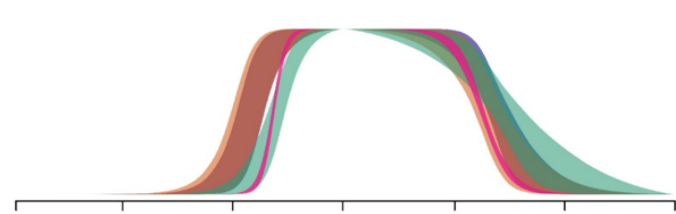

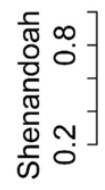

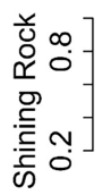

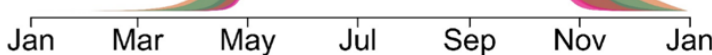

Time

- GOES NDVI

- PhenoCam GCC

- MODIS NDVI MODIS EVI

Figure S6: Rescaled 95\% credible intervals for the phenology fits for 2019 for all data sources and sites. 